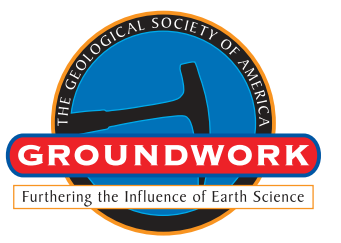

\title{
GSA Statement on Diversity and a Challenge to the Society, Geoscience Departments, and the Geoscience Community at Large
}

Bradley D. Cramer, David W. Peate, Dept. of Earth and Environmental Sciences, University of Iowa, Iowa City, Iowa 52242, USA; and Matthew R. Saltzman, School of Earth Sciences, The Ohio State University, Columbus, Ohio 43210, USA

\section{INTRODUCTION}

On 1 June 2020, the Geological Society of America (GSA) posted the following message on its message board:

This past week we witnessed a sadly familiar scene in the United States with the senseless death of George Floyd in Minneapolis. He joins other victims of overt racism and systemic discrimination. We all feel the pain, anger, and sadness of these tragedies, but it is particularly acute for our African American members, their families, and other People of Color. GSA stands with all of our colleagues facing these injustices and is committed to challenging and changing the biases that lead to discriminatory practices against People of Color.

We condemn discrimination and harassment in any form, and are actively working to promote the ideals and principles of our position statements on Diversity in the Geosciences Community and Removing Barriers to Career Progression for Women in the Geosciences. GSA's Code of Ethics and Professional Conduct gives process to our vision and purpose for representing the best that our science can be.

The pain of recent events motivates us to push harder to advance diversity, equity, and inclusion in the geosciences. Addressing systemic oppression requires both immediate and long-term efforts while humbly acknowledging that the geosciences remain one of the least diverse academic disciplines in the sciences. In the weeks and months ahead, GSA leadership will be furthering our efforts toward building a more diverse, respectful, and inclusive space for all science, and scientists, to thrive. We ask the GSA membership to join us and to challenge us to make a real difference.

We applaud GSA for making a public statement regarding these painful events; however, we want to focus on two significant statements in this message. First, the acknowledgment that geoscience remains one of the least diverse science discipline.
Secondly, the call to challenge GSA to make a real difference.

\section{THE PROBLEM}

GSA, and the geosciences in general, continue to gloss over the fact that we remain far behind even other STEM disciplines in our diversity (Fig. 1; also see Bernard and Cooperdock, 2018). Whereas this was stated in the 1 June note, nowhere in the official GSA position statement on Diversity in the Geosciences Community is this fact acknowledged. Instead, GSA pleads ignorance of the magnitude of the problem: "There is a lack of quantitative and qualitative understanding of the current status of diversity-related issues and conditions in and associated with GSA." This statement is made in spite of the fact that the National Science Foundation, the American Geosciences Institute (AGI), the Journal of Geoscience Education, and even GSA itself have been publishing data and articles for more than 40 years that point this out (e.g., Gillette, 1972; O'Connell and Holmes, 2011; Stokes et al., 2014). GSA can and must do better, and we all need to take a long hard look at our discipline, our Society, and ourselves.

Geoscience is the least diverse discipline in science. There are many reasons why this is the case, and attempts at solving this issue have not been successful (NSF, 2001; Bernard and Cooperdock, 2018; Dutt, 2020). The total number of underrepresented minority (URM) geoscientists is unacceptable. Rarely have 20 or more Ph.D.s been earned by Black geoscientists in any given year nationwide. Rarely has that number been above 40 for M.S. degrees in a year. Fewer than $4 \%$ of tenured or tenure-track faculty are URM in the top 100 U.S. earth science departments (Nelson, 2017). We must provide more opportunities for URM students to see themselves reflected in the face of the professor in front of the classroom and as representative role models and leaders in their field. Most of the GSA position statement on diversity is boilerplate and lacks specific actions. It talks about embracing diversity, but much of the document focuses on geoscience education and outreach to policy makers. The Society can and should take concrete positions and actions on diversity, equity, and inclusion and lead by example.

\section{COMMIT TO REAL CHANGE}

The Society and our discipline cannot continue to overlook this issue, particularly as it pertains to Black, Latinx, and First Nations communities. Even AGI, which has done more than any of the U.S. geoscience societies to address this issue still softens the problem: "Outside of the representation rate of Black and African American geoscience graduate students, the representation rates of racial and ethnic underrepresented groups in the geosciences are similar to STEM-wide trends, indicating diversity issues in the geosciences are not unique" (Wilson, 2018). To begin with, Black representation is worse in geoscience than other STEM disciplines. Secondly, this statement has been used by STEM disciplines for decades to throw up their collective hands and not address the issues. GSA, geoscience departments, and geoscientists must accept these facts before we can move forward to create real change.

The negative health and environmental impacts of geoscience industries, such as energy and mineral resource extraction, production, and disposal disproportionally fall on URM communities. Decades, and in some cases centuries, of zoning laws and

GSA Today, v. 31, https://doi.org/10.1130/GSATG472GW.1. CC-BY-NC. 


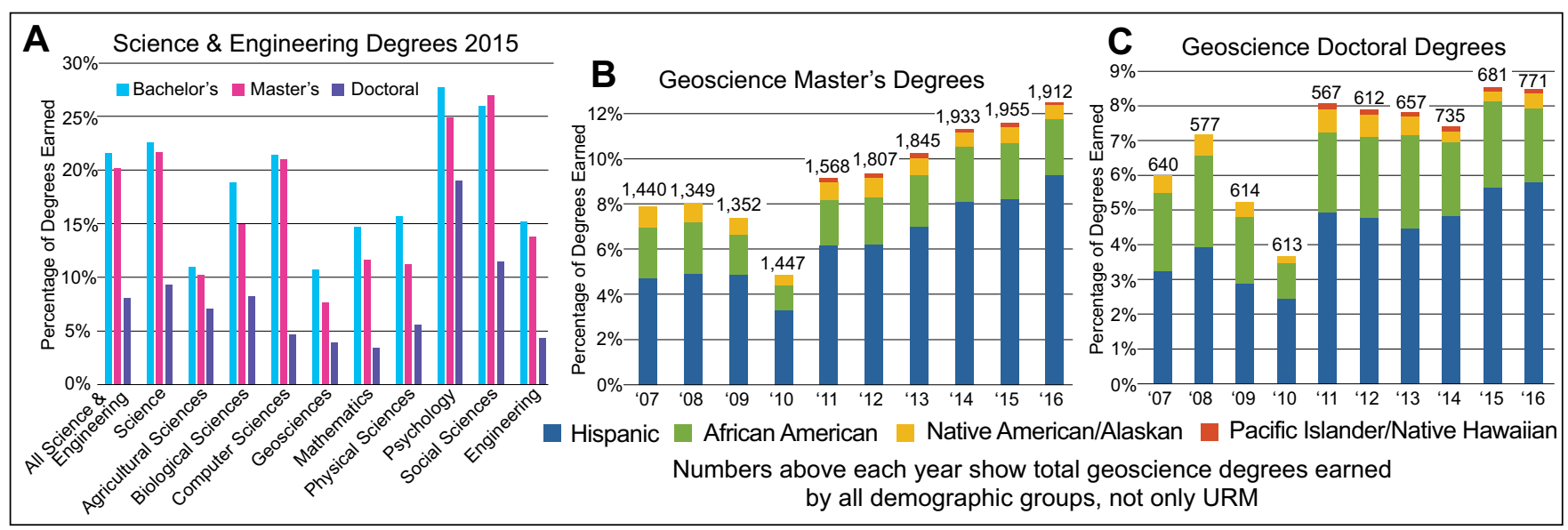

Figure 1. (A) Percentage of STEM degrees earned by underrepresented minorities, (B) Percentage of geoscience M.S., and (C) Ph.D. degrees earned by underrepresented minorities (URM). Figures after Wilson (2019) and total geoscience M.S. and Ph.D. degrees in panels (B) and (C) from the U.S. Department of Education, National Center for Education Statistics (https://nces.ed.gov/programs/digest/d19/tables/dt19_325.72.asp?current = yes).

redlining bring us to a present day where the intersection of geoscience and society is likely more important to everyday life in URM communities than other demographics. In fact, a range of geoscience issues, including natural hazards, water quality and quantity, and climate change are all inextricably linked to topics of race, equity, justice, and marginalization of URM communities. These are the communities GSA, and all of us as geoscientists, should be doing everything in our power to help to train (and retain) as the next generation of geoscientists, and diverse voices are critical in the search for just and equitable solutions. Yet, where is there any mention of real partnership with Historically Black Colleges and Universities (HBCUs), Hispanic Serving Institutions (HSIs), the Hispanic Association of Colleges and Universities (HACU), or Tribal Colleges and Universities (TCUs) in GSA's actions or position statement? Where is there any mention of real partnership with organizations such as the National Association of Black Geoscientists (NABG), American Association of Blacks in Energy (AABE), Society for Advancement of Chicanos/Hispanics and Native Americans in Science (SACNAS), Society of Mexican American Engineers and Scientists (MAES), GeoLatinas, American Indian Science and Engineering Society (AISES), Geoscience Alliance, or National Consortium for Graduate Degrees for Minorities in Engineering and Science (GEM)? Real and meaningful two-way partnerships that produce actions, and that do not only exist on paper, are critically needed.

We strongly encourage GSA, geoscience departments, and geoscientists to take lead- ership roles on a range of issues to begin to commit to real and lasting change. A few examples of such actions could include:

- Advocating for immediate and significant increases in the number of URM faculty in geoscience departments nationwide through inclusive and equitable hiring practices (e.g., Tatum, 2003);

- Creating real two-way partnerships with HBCUs, HSIs, the HACU, and TCUs;

- Creating real partnerships with organizations such as NABG, SACNAS, MAES, GeoLatinas, AISES, GEM, Geoscience Alliance, and others;

- Creating inclusive mentoring programs, perhaps with these organizations;

- Advocating for the removal of GRE requirements to geoscience graduate programs and adopting a "holistic" evaluation process (Kent and McCarthy, 2016);

- Either directly paying for, or advocating for the removal of, graduate school application fees for URM students (similar to the American Geophysical Union's Bridge Program);

- Mandating diversity in panels and plenary lectures at meetings as well as in awards;

- Ensuring that the burden of creating this change and revising the position statement and actions of GSA and the geoscience community do not fall exclusively on URM members of GSA - these are issues that must be addressed by the entire executive leadership of the Society, as well as all members;

- Identify and remediate systemic roadblocks to diversity within geoscience curricula;

- Identify and promote best practices and successful programs that succeed in engaging, empowering, and promoting URM geoscientists; and

- Listen deeply to the experiences of URM geoscientists and commit to meaningful change.

This is only an initial list, and we all need to continue to develop more direct and concrete actions. An online petition, "Geoscientists: Call for a Robust Anti-Racism Plan for the Geosciences" (http://chng.it/ gZ28ZNHcnS), and the resources at https:// 500womenscientists.org/updates/2020/ 6/1/take-action inspired this article, and they include a more comprehensive list of actions in which we all can and should engage. We sincerely thank the organizers of the petition and strongly encourage all geoscience societies, and all geoscientists, to read the petition and consider adding their support. GSA can, should, and must take a leadership role in this issue, and it is only through the concerted efforts of the executive and membership of the Society, geoscience departments across the country, and all of us as geoscientists that we can begin to be the change we so desperately need.

\section{ACKNOWLEDGMENTS}

We thank two anonymous reviewers for strengthening this manuscript and GSA for facing these challenges. This work is an outcome of National Science Foundation-Improving Undergraduate STEM Education (IUSE) Grant GP-IMPACT-1600429.

\section{REFERENCES CITED}

Bernard, R.E., and Cooperdock, E.H.G., 2018, No progress on diversity in 40 years: Nature Geoscience, v. 11, p. 292-295, https://doi.org/10.1038/ s41561-018-0116-6.

Dutt, K., 2020, Race and racism in the geosciences: Nature Geoscience, v. 13, p. 2-3, https://doi.org/ 10.1038/s41561-019-0519-z. 
Gillette, R., 1972, Minorities in the geosciences: Beyond the open door: Science, v. 177, p. 148-151, https://doi.org/10.1126/science.177.4044.148.

Kent, J.D., and McCarthy, M.T., 2016, Holistic review in graduate admissions: A report from the Council of Graduate Schools: Washington, D.C., Council of Graduate Schools, 48 p.

NSF (National Science Foundation), 2001, Strategy for Developing a Program for Opportunities for Enhancing Diversity in the Geosciences (NSF 0153): Alexandria, Virginia, National Science Foundation, https://nsf.gov/geo/diversity/geo_diversity_ strategy_document_jan_01.jsp.

Nelson, D.J., 2017, Diversity of science and engineering faculty at research universities, in Nelson,
D.J., and Cheng, H.N., eds., Diversity in the Scientific Community Volume 1: Quantifying Diversity and Formulating Success: American Chemical Society, v. 1255 , p. $15-86$, https://doi.org/ 10.1021/bk-2017-1255.ch002.

O'Connell, S., and Holmes, M.A., 2011, Obstacles to the recruitment of minorities into the geosciences: A call to action: GSA Today, v. 21 , no. 6 , p. 52-54, https://doi.org/10.1130/G105GW.1.

Stokes, P.J., Levine, R., and Flessa, K.W., 2014, Why are there so few Hispanic students in geoscience: GSA Today, v. 24, no. 1, https://doi.org/ 10.1130/GSATG176GW.1.

Tatum, B.D., 2003, Why are all the Black kids sitting together in the cafeteria?: And other conver- sations about race: New York, Basic Books, $294 \mathrm{p}$.

Wilson, C.E., 2018, Race and ethnicity of U.S. citizen geoscience graduate students and postdoctoral appointees, 2016: Washington, D.C., American Geosciences Institute, Geoscience Currents, no. 132.

Wilson, C., 2019, Status of the geoscience workforce 2018: Washington, D.C., American Geosciences Institute, $178 \mathrm{p}$.

MANuSCRIPT RECEIVED 9 June 2020

REVISED MANUSCRIPT RECEIVED 13 OCT. 2020

MANUSCRIPT ACCEPTED 16 OCT. 2020

Editor's Note: GSA has made several diversity-related updates since this paper was first written. The latest information is online at https://www.geosociety.org/ diversity. Of note, a leadership retreat on diversity, equity, and inclusion (DEI) was held in August 2020 that included GSA's Executive Committee, GSA staff, and 20 invited diversity leaders in the geosciences. That discussion, led by facilitator and expert trainer Dr. Nita Mosby-Tyler of The Equity Project LLC, identified activities likely to have a measurable and lasting impact. Additional details, including priorities and the existing DEI initiatives in GSA's strategic plan, are online. 